\title{
Independent expeditions and Antarctic tourism policy
}

\section{Carl Murray and Julia Jabour}

Antarctic Climate \& Ecosystems CRC and Institute of Antarctic and Southern Ocean Studies, University of Tasmania, Private Bag 80, Hobart, Tasmania 7001, Australia

Received March 2004

ABSTRACT. Discussions about the management of non-governmental activities in Antarctica have been handicapped by a lack of clarity in terminology. The term 'tourism,' for example, is used in a catch-all manner to describe activities as widely divergent and incommensurable as overflights by commercial jetliners and solo ski traverses of the ice cap. Recent debate about stricter regulation of independent expeditions has been similarly confused. This paper examines these definitional hurdles and offers a broad categorization of activities in Antarctica. An overview of recent independent expeditions is then given and issues are discussed. It is suggested that, to date, the terms of the debate have been set by the most powerful vested interests in Antarctica and that the discussion itself has been polarized. The paper does not prescribe policy but indicates alternative points of view and argues that the strict regulatory approach increasingly favoured by some national programs is out of all proportion to the size of potential problems and could diminish traditions of cooperation, non-proprietorship, and the adventurous spirit, which have uniquely characterized human endeavour in Antarctica.

\section{Contents}

Introduction

Antarctic tourism policy

Terminology

Recent independent expeditions

Discussion

Conclusion

Acknowledgements

References
309

309

310

313

314

316

316

316

\section{Introduction}

As Antarctica has become increasingly accessible to visitors in recent decades - to the point where more tourists than scientists now arrive in the region each year - so too has concern developed about the proper regulation of the activities of visitors not associated with governmental programs. While these people have usually been categorized as tourists of one type or another, this paper argues that this umbrella term is not always appropriate. A larger and more organized Antarctic tourism industry, highly conscious of operating within the regulatory framework of the Antarctic Treaty System and of the priority that system has always accorded to government-sponsored scientific research, has naturally sought to establish its credentials as a responsible actor in the region. Its success is attested by the regular endorsements the International Association of Antarctica Tour Operators (IAATO) now receives from national programs, and by the fact that 'several [Treaty] Parties... have initiated the practice of denying visits [to their bases] by non-IAATO members' (IAATO 2002: $5)$. Indeed it appears as if questioning of the validity of mainstream tourism in Antarctica may no longer be possible (Scott 2001: 967-968). Consequently there are at present two large and powerful groups directing most human activity in Antarctica as well as debate about future policy for the region: national science programs and IAATO. This paper considers some of the implications of this situation for others who may wish to visit the continent, in particular independent expeditions, which have recently attracted criticism from both groups. First, however, the development of Antarctic tourism policy is briefly reviewed and the terminology of the debate examined.

\section{Antarctic tourism policy}

Concerns about tourists in Antarctica were expressed formally as early as the fourth Antarctic Treaty Consultative Meeting (ATCM) in 1966, when questions were raised about how their activities might 'prejudice the conduct of scientific research, conservation of fauna and flora and the operation of Antarctic stations' (ATCPs 1966: Recommendation IV-27). Tourism was being acknowledged as 'a natural development' in the region but one that required regulation, and accordingly preliminary guidelines were formalized (ATCPs 1975: Recommendation VIII-9, 1979: Recommendation X-8). However the withdrawal of a draft recommendation in 1983, due to a lack of agreement concerning jurisdiction over non-governmental activities, hinted at the confusion that began to cloud the discussions (United States 2002: 315).

Until the mid-1980s tourist numbers had been modest, but in the following decade they escalated by $800 \%$ (Tracey 2001: 48). At the same time, after six years of negotiation, the Antarctic Treaty Consultative Parties (ATCPs) rejected the Convention on the Regulation of Mineral Resource Activities in favour of comprehensive protection of the region through the Protocol on Environmental Protection to the Antarctic Treaty (Madrid Protocol). Thereafter all activities in the Antarctic would be viewed through the lens of their potential impact on the environment. The steep rise in tourist numbers and the generally unregulated nature of tourism challenged the ATCPs' long-standing assertion of exclusive competence in the conduct and regulation of activities in the Antarctic, and from 1992 there was a concerted effort by some to 
have an annex dealing specifically with tourism added to the Madrid Protocol. After considerable debate, this proposal was rejected, and it was agreed instead to trust in the omnipotence of the Protocol itself: 'All parties stressed that the Protocol and its Annexes apply to all activities in Antarctica, including tourism and non-governmental activities' (ATCPs 1992: paragraph 111).

Following the failure of the proposal for a tourism annex, the ATCPs largely abdicated responsibility in favour of self-regulation by the tourist industry within a framework of formal guidelines (ATCPs 1991: Recommendation XVI-13, 1994: Recommendation XVIII-1). Conveniently, this change of direction coincided with the establishment of IAATO, a US-registered non-governmental organization, which since 1991 has provided reports and statistics to ATCMs and now enjoys 'invited expert' status at the meetings. In the view of Richard Herr (1996: 105), IAATO's formation 'represented as much an attempt by the majority of tour operators to improve their capacity at self-regulation as to influence the regulations likely to be pursued by the Consultative Parties.' IAATO currently represents member companies from 11 countries and describes itself as advocating, promoting, and practising safe and environmentally responsible private-sector travel to the Antarctic (IAATO, Undated a). The organization takes pride in its support for national scientific research programs (IAATO, Undated b), although on many occasions these arrangements are made on a commercial basis (IAATO, Undated c). Member companies agree to abide voluntarily by the guidelines adopted by ATCMs and IAATO, and the only sanction IAATO can impose for a breach is to reduce membership status to probationary. Critics of industry self-regulation have pointed out the potential shortcomings of this arrangement; however additional legal obligations exist in some states.

Although the issue of tourism has now been formally on the agenda of ATCMs for more than 30 years, this has not often led to outcomes in the shape of meeting declarations (United States 2002). Meanwhile the allure of Antarctica has continued to grow, and the kinds of experiences people seek there have diversified. This trend is likely to continue, and more careful consideration of these matters is therefore long overdue. Presumably in recognition of this, Decision 5 (2003) of the ATCM in Madrid in June 2003 called for an Antarctic Treaty Meeting of 'Experts on Tourism and Non-governmental Activities' to be convened in Norway in March 2004. It is expected that those discussions will be reported to the ATCM in Cape Town in May 2004.

\section{Terminology}

ATCM discussions to date have raised a number of important questions, including access to Antarctica and research stations, the monitoring of tourist activities, the application of environmental regulations, and safety and emergency response measures. However at no stage have the critical terms 'tourist,' 'tourism,' 'non-governmental activities,' 'adventure tourism,' 'expedition,' or 'support' been substantively defined. This omission has contributed to the confusion of the debate and the inconsistencies in the positions taken, and thus hampered the formulation of regulations acceptable to all stakeholders. (The term 'tourism,' for example, has been broadly applied to such disparate activities as overflights by commercial jetliners and solo ski traverses of the ice cap.) While it is expected that all tourists and tour operators belonging to IAATO or to states that are Contracting Parties to the Treaty and Protocol will abide by the provisions of these instruments, responsibility for implementing legal obligations rests with the states, and in this context clear and agreed terminology concerning all non-governmental activities is vital.

The 1959 Antarctic Treaty itself makes no specific reference to tourism. This is not surprising, given that tourists in the region were then virtually non-existent and that the Treaty's overriding concern was to throw a cordon of peace around the globe at $60^{\circ} \mathrm{S}$ in the face of the sabre-rattling generated by territorial claims and the Cold War. By the time the text of the Madrid Protocol was finalized in 1991, tourist numbers were at about 5000 annually and rising rapidly (Enzenbacher 1992, 1994), and attention had shifted to environmental protection. The word 'tourism' now appears four times: in Articles 3, 8, 15, and in Annex III. On each occasion the word is part of a phrase comprehending all human activity in Antarctica:

Activities undertaken in the Antarctic Treaty area pursuant to scientific research programmes, tourism and all other governmental and non-governmental activities in the Antarctic Treaty area for which advance notice is required under Article VII (5) of the Antarctic Treaty, including associated logistic support activities... (Protocol Article 8.2; in Article 3 the phrase 'in accordance with' is substituted for the word 'under.')

Treaty Article VII (5) requires that Contracting Parties give one another advance notice of stations and military personnel or equipment in Antarctica and 'all expeditions to and within Antarctica.' In the historical context of the Treaty the term 'expedition' referred to large government-sponsored science programs. The Protocol's concern, however, is with the different types of 'activity' taking place in Antarctica, and since the Parties have subsequently agreed that this instrument applies to all activities there (ATCPs 1992: paragraph 111), it is unnecessary to seek a more precise definition of 'expedition.' This paper therefore employs the term in its ordinary sense as 'a journey, voyage, or excursion made for some definite purpose' (Oxford English Dictionary 1989: 5, 560), which in the case of Antarctica is taken to mean the act of going there - for whatever purpose, by whatever number of people, and by whatever means. From the Protocol's text is taken, as the basis of categorization, its division of all activities in Antarctica into governmental (with its subsets of 'scientific research' and 'other') and non-governmental (with its subsets of 'tourism' and 'other'). The Protocol 

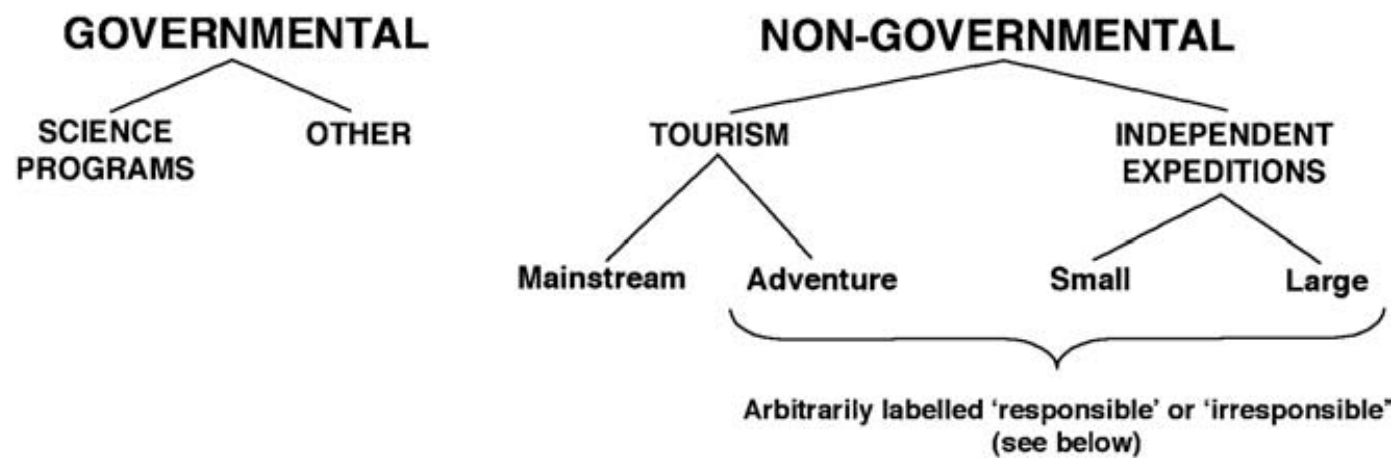

Fig. 1. Activities in the Antarctic Treaty area.

itself offers no further guidelines for the interpretation of these terms, and as Shirley Scott has observed in the context of legal means for managing Antarctic tourism, 'one basic challenge... is that of how to define tourism in a way that distinguishes between tourist activities and other non-governmental activities in Antarctica' (Scott 2001: 968).

There is no universally accepted definition of what a tourist or tourism is, and some statements of their meaning are so broad as to be unhelpful in the Antarctic context as a means of differentiating between any types of activity there. The World Tourism Organization, for example, defined tourism as: 'The activities of persons traveling to and staying in places outside their usual environment for not more than one consecutive year for leisure, business, and other purposes' (Gee and Fayos-Solá 1997: 5). This would make the vast majority of humans in Antarctica including most scientists and support staff - tourists. Mathieson and Wall (cited in Bauer 2001: 6) offered an equally expansive definition: 'tourism is the temporary movement of people to destinations outside their normal places of work or residence, the activities undertaken during their stay in those destinations, and the facilities created to cater to their needs.' Definitions as broad as these, unless further qualified, could lead to absurdities such as regarding those in refugee camps who are unsuccessful in finding a new country of residence and are subsequently returned to their country of origin as tourists. Tourism has been subdivided into categories such as mass tourism or alternative tourism, and into sub-categories such as adventure, nature-based, wildlife, and ecotourism (Newsome and others 2002: 13). Weaver and Oppermann (2000: 48) proposed six sub-categories based on location (domestic or international), direction (inbound or outbound), and length of stay. Others have classified tourists in terms of motives: leisure, business, visiting family and friends, pilgrimage, sport, health, and study (Weaver 1998; Urry 1990). It is likely, therefore, that definitions will have a utility specific to the user of the term. In the Antarctic context, for example, an Australian Senate Committee chose to regard as tourism 'all existing human activities other than those directly involved in scientific research and the normal operations of Antarctic bases' (Commonwealth of Australia 1989: 3). Thus commer- cial tourist operations, non-profit, non-governmental expeditions, and even the recreational activities of scientific personnel were considered to be tourism. By contrast, Antarctic tourism researcher Thomas Bauer restricted tourism to the commercial (for profit) transport (including accommodation and catering) of nongovernment travelers to and from Antarctica for the purpose of pleasure' (2001: 15). This definition has the advantage of including the motive of pleasure, which is essential to the common understanding of the word 'tourist' (Oxford English Dictionary 1989: 18, 306).

Taking a cue from the wording of the Madrid Protocol, and mindful of the hazards and limitations of the undertaking, the authors propose their own classification of human activities in the Antarctic Treaty area (Fig. 1).

The division of all activity into the categories of governmental and non-governmental is generally accepted. (It should be pointed out that 'governmental' in this context refers only to ATCPs. Even governmentsponsored expeditions of other states are regarded as 'non-governmental' because they are not bound by the same legal obligations as Treaty Parties.) The first subset of the governmental category comprises scientific research personnel and associated logistics support staff and official observers (Boczek 1988: 462). The second subset, 'other governmental,' embraces those whose activities are sanctioned or sponsored by ATCPs but who are not associated with a scientific program: media representatives, government ministers, artists, writers, and musicians, for example. (The authors do not agree with the US State Department's inclusion of the last three under the heading of 'tourism and other non-governmental activities' (United States 2002: 306) in cases where their primary motive is not simply recreation and their passage to Antarctica is provided by a government program.)

Categorization of non-governmental activities demands additional refinement. This paper's use of 'tourist' draws on the common meaning of the word and the approaches of Weaver, Urry, and Bauer. Two factors are considered: the motive for and the mode of travel. The former pays particular attention to the extent to which pleasure and recreation are the principal motives, and the latter to the extent to which the mode of travel relies on commercial services. (Thus it is not considered helpful, if 
Table 1. Categories of non-governmental actors.

\begin{tabular}{|c|c|c|}
\hline Category & Motive & Mode \\
\hline $\begin{array}{l}\text { Mainstream } \\
\text { tourists }\end{array}$ & $\begin{array}{l}\text { Relatively low-risk recreational activities, } \\
\text { such as viewing from aircraft or } \\
\text { transferring from cruise ship to view } \\
\text { wildlife. }\end{array}$ & $\begin{array}{l}\text { Use (or are employed by) scheduled, mostly } \\
\text { IAATO-affiliated, commercial operations, for } \\
\text { example overflights and cruises, whether } \\
\text { or not they land tourists on the continent. }\end{array}$ \\
\hline $\begin{array}{c}\text { Adventure } \\
\text { tourists }\end{array}$ & $\begin{array}{l}\text { More active, higher-risk recreational } \\
\text { activities (in some cases extreme } \\
\text { sports) in an Antarctic context, such } \\
\text { as kayaking, sky-diving, mountain } \\
\text { climbing. }\end{array}$ & $\begin{array}{l}\text { Sometimes originators of activity, but } \\
\text { mainly use (or are employed by) commercial } \\
\text { services, principally Antarctic Logistics and } \\
\text { Expeditions (ALE), which now incorporates } \\
\text { Adventure Network International (ANI), for } \\
\text { transport, victualling, guides, accommodation, } \\
\text { and search and rescue (SAR) back-up. }\end{array}$ \\
\hline $\begin{array}{l}\text { Small } \\
\text { independent }\end{array}$ & $\begin{array}{l}\text { Usually includes a specified goal, such } \\
\text { as breaking a record or raising funds } \\
\text { for charity; not principally seeking } \\
\text { high-risk recreation. }\end{array}$ & $\begin{array}{l}\text { Solo or with few others; originator of activity, } \\
\text { which is usually one-off; non-commercial and } \\
\text { essentially independent of governmental } \\
\text { or commercial operations, but may use some } \\
\text { commercial services for support, such as } \\
\text { transport, SAR back-up, or fuel delivery; } \\
\text { often have some private sponsorship. }\end{array}$ \\
\hline $\begin{array}{l}\text { Large } \\
\quad \text { independent }\end{array}$ & $\begin{array}{l}\text { Various (category also includes } \\
\text { expeditions of non-governmental } \\
\text { organizations and of governments that } \\
\text { are not Contracting Parties); sometimes } \\
\text { includes a specified goal; not principally } \\
\text { seeking high-risk recreation. }\end{array}$ & $\begin{array}{l}\text { Groups, often considerably larger than small } \\
\text { independent expeditions; originators of the } \\
\text { activity, which is usually one-off; non- } \\
\text { commercial and generally more independent } \\
\text { than adventure tourists, but may use some } \\
\text { commercial services. }\end{array}$ \\
\hline
\end{tabular}

the term tourism is to have practical value in Antarctica, to refer to those associated with national science programs as 'business tourists,' as is sometimes done in conformity with the broadest definitions.) Tourists are further divided into the subsets of 'mainstream' and 'adventure.' The Protocol's 'other non-governmental' category is termed 'independent expeditions,' and these are divided into 'small' and 'large.' Four categories of non-governmental actors emerge, as shown in Table 1.

A certain degree of overlap will occur between categories without necessarily invalidating them. Large independent expeditions, for example, may at times operate in a mode similar to adventure tourism but are distinguished from the latter by different motives. Similarly, national programs may on occasion use commercial services for the transport of personnel, who cannot thereby be regarded as tourists because tourism is not their primary motive. A single example is now given to illustrate how more careful classification could help clarify discussions.

In a presentation to a tourism workshop sponsored by Antarctica New Zealand in June 2000, Eric Chiang, then head of operations of the United States Antarctic Program, cited six cases of 'incidents involving tourist activities' (2000: 26). These included the crash of Air New Zealand's Flight 901 into Mount Erebus in 1979; the running aground a decade later of the Argentine resupply and tourist vessel Bahia Paraiso near the US Palmer station; the deaths of one Austrian and two American skydivers at the South Pole in 1997; the helicopter rescue of members of the 1986/87 'Footsteps of Scott Expedition'; the rescue in 1993 of members of a Norwegian expedition that had attempted to recover Amundsen's tent at the South
Pole; and the stabilization and rapid removal to New Zealand of an Australian tourist who suffered a heart attack while on a tour of McMurdo station. While the umbrella term 'tourist activities' was used to group all these incidents, according to the classification in this paper the first and sixth were examples of mainstream tourism, the second of adventure tourism, the third and fourth of large independent expeditions, and the fifth a mixture of a science program and mainstream tourism. To deal simultaneously with such a farrago of activities will inevitably confuse discussions about management. Chiang's address concluded with an expression of concern about 'the increasing popularity of adventure tourism' on the grounds that 'the real challenge of adventure tourism is not to accommodate risks but to overcome them' (2000: 28). He did not, however, state which, if any, of his six examples he believed belonged to that category.

The term 'adventure tourism' has hitherto been a source of particular confusion. As IAATO (2003) and others have noted, it has never been clearly defined. Consequently it has been employed with a range of meanings, mostly vague, according to the user's need. It is often loosely combined with the word 'extreme' (ATCPs 2003: Decision 5) or the epithet 'adventurer,' and the Council of Managers of National Antarctic Programs (COMNAP) added the descriptor 'high risk' when it first expressed concern about what it broadly termed 'adventure tourism' (COMNAP 2002: paragraph 15). In this paper's classification, adventure tourism is principally a commercial activity, and extreme sports those 'performed in a hazardous environment and involving great physical risk' (New Oxford Dictionary 
of English 1998: 652) - are only a component of the category. While it can be argued that Antarctica is always a hazardous environment, the degrees to which people choose to expose themselves to that danger vary greatly; and unlike most passengers on Antarctic cruise ships, practitioners of extreme sports deliberately expose themselves to great physical risk. Antarctic Logistics and Expeditions (ALE; now incorporating Adventure Network International or ANI), the largest provider of adventure tourism in Antarctica, calls the experiences it offers - 'from private flights ... and photo safaris ... to climbing... [and] commemorative journeys' — 'safe' (ANI, Undated a), although the company also provides a category of more challenging programs that it terms Extreme (ANI, Undated b).

A further problem resulting from the lack of definition of adventure tourism and its associated adjectives has been that they have been applied indiscriminately to a variety of categories, increasingly to any non-governmental activity in Antarctica that is not sponsored by IAATO. Thus independent expeditions are generally lumped together with various others in the 'adventure tourist' category, whereas according to the present classification they are not tourists at all. For similar reasons, Bauer, while claiming to offer 'a comprehensive analysis of the tourism phenomenon in the Antarctic context' (2001: 119), makes only passing reference to independent expeditions 'because their activities are private endeavors rather than commercial tourist ventures' (2001: 110). The authors prefer 'independent' to 'private' because it suggests that the activity does not rely mainly on commercial services and because commercial activities are also often referred to as 'private' in the sense of 'non-governmental.'

The introduction alluded to the dichotomy that has emerged between mainstream tourism and the other categories of non-governmental activity in Antarctica, and the fact that the latter have recently attracted criticism from some national programs and from IAATO. This development has gone hand in hand with use of the imprecise and value-laden terminology previously discussed, and has now led to the suggestion that all non-governmental activities that are not conducted by IAATO are suspect and therefore require strict regulation. This view was exemplified by the call at ATCM XXVI in 2003 for "the adoption of stringent guidelines to control unsupervised “adventure tourism" activities' (United Kingdom 2003). The paper now considers the implications of this situation for the particular case of independent expeditions, noting again that these have been distinguished from tourists, mainstream or adventure. First a survey of recent activity is presented, followed by an examination of issues.

\section{Recent independent expeditions}

Accurate information about the numbers and exact nature of independent expeditions in Antarctica is difficult to obtain. Antarctic Non-Government Activity News (ANAN), the only comprehensive record of non-governmental activity, was published from 1 September 1999 to 24
June 2003 (the electronic archive ends at 21 May 2003). However in a climate where the entire range of non-governmental activities, and non-IAATO activity in particular, is controversial, the facts are sometimes disputed. Independent expeditions, especially if they have experienced problems, often attract considerable press coverage and some of this is inevitably speculative. With these caveats, an overview of recent activity is given as reported in ANAN and, after it ceased publication, in the press.

In 1999 Norwegians Rolf Bae and Erik Sønneland successfully completed an unsupported traverse of the continent but arrived at Ross Island with little food and were fed and accommodated at Scott Base until they were able to leave on a tourist ship. In the formal documentation submitted prior to their expedition, they had stated only that a traverse would be made to the South Pole and made no reference to crossing the continent (ANAN Archive: 41/04). In the same season two small independent expeditions flew to the Antarctic Peninsula without incident (ANAN Archive: 14/07; 29/05).

The following year Australian Peter Bland, injured in an avalanche on the Antarctic Peninsula, was rescued after the combined efforts of his support yacht, a tourist ship, and the Chilean national program (ANAN Archive: 41/01; 49/04). (As recounted in the film Hell on ice (Lindsay 2004), this expedition, discouraged by the Australian Antarctic Division, had aspects that might justify the label 'extreme.')

In the austral summer of 2001-02, a large independent group of 14 Russian tourists and officials was stranded at the South Pole for two days when their plane would not start. They were housed and fed at Amundsen-Scott and arrangements were made to fly them out at their own expense (ANAN Archive: 79/05). In the same season, two ANI-supported traverses to the Pole were reported, and were apparently completed without incident (ANAN Archive: 65/03).

Towards the end of 2002, three more traverses were en route for the South Pole (ANAN Archive: 87/06), and the first of what was to become a series of controversial independent expeditions by aviators took place. Solo French pilot Henri Chorosz made a forced landing on sub-Antarctic Marion Island during an attempt to be the first to circle the Earth via both poles in a single-engine aircraft (ANAN Archive: 88/01; Le Quotidien de Réunion 18 December 2002). According to the official report (Yelverton, undated), the aircraft was badly damaged on landing but the pilot escaped without serious injury and stayed at the South African station for 10 days. The expedition was reportedly not known to French, South African, New Zealand, or United States authorities (ANAN Archive: 88/01). Questions were raised about the aviator's arrangements for refuelling during his journey, but neither the newsletter (ANAN 2003: 91/07) nor the authors have been able to confirm these with the pilot himself. Two months after this incident, a UK-registered helicopter was forced into the ocean $60 \mathrm{~km}$ north of 
Livingston Island in the South Shetlands. The two British pilots were rescued from their life raft by the Chilean navy. ANAN raised questions about their intended destination (ANAN 2003: 91/01) and also asserted that the UK national program was unaware of the existence of the expedition prior to the emergency (ANAN 2003: 93/03).

The 2003-04 season saw three much-publicized independent expeditions by aviators. UK pilot Polly Vacher planned to fly a single-engine aircraft around the world, but her first attempt at the Antarctic leg was defeated by headwinds. She was subsequently forced to abandon the Antarctic crossing when she was unable to have fuel for a second attempt positioned in the Patriot Hills. Before it ceased publication, ANAN enquired about the expedition's refuelling and search-and-rescue (SAR) arrangements without being able to confirm details of these, and also reported various arrangements the pilot had apparently made with ANI, Antarctica New Zealand, the tourist vessel Kapitan Khlebnikov, and the UK's Rothera station (ANAN 2003: 64/11; 86/13; 91/07). In the same summer Australian Jon Johanson landed at Scott/McMurdo base with insufficient fuel to allow him to return to New Zealand after having become 'the first person to fly solo in a fixed-wing, home-made aircraft over the South Pole' (The Age (Melbourne) 11 December 2003). The aviator claimed that stronger than anticipated headwinds had prevented him from continuing to Argentina as planned, although this intention was reportedly disputed by Antarctica New Zealand. That organization criticized the aviator as 'irresponsible' and, along with US authorities at McMurdo, refused to sell him fuel but offered to fly him out and ship back his aircraft, both at his own expense. Johanson declined this offer and finally completed his return flight when Vacher released fuel she had stored at McMurdo for her own expedition (The Age (Melbourne) 16 December 2003). Criticisms of Johanson together with the pilot's defence were widely and vigorously reported in the press. A third independent expedition took to the air in New York. Helicopter pilots Jennifer Murray and Colin Bodill planned to circle the Earth via both poles but, after reaching the South Pole, crashed in the region of Patriot Hills. They were rescued by ALE in accordance with prior contingency arrangements and then flown to Punta Arenas, where Bodill required surgery. In contrast to the criticism it has levelled at Johanson's expedition, IAATO, of which ALE is a member company, stated that Murray's expedition was well-planned and that the rescue was 'an amazing success story,' in part because no assistance was required from the UK or US programs (Denise Landau, executive secretary, IAATO, personal communication, 22 December 2003).

Apart from these expeditions, it is not known how many others may have attempted to sail yachts, paddle kayaks, or fly small aircraft in the Antarctic. What is clear is that the number of such independent individuals is minute in comparison with the thousands brought into the area annually by government programs and mainstream tourism. Statistics on the former are not available but those for mainstream tourism in Antarctica are supplied by IAATO. Excluding ALE/ANI and the category 'sailing vessel or small boat,' the preliminary figures for the total number of individual visits by passengers, staff, and crew recorded by IAATO in the 2003/04 season was 44,266 (Denise Landau, executive secretary, IAATO, personal communication, 22 April 2004).

\section{Discussion}

\section{Reasons for concern}

At the 2002 ATCM in Warsaw, COMNAP expressed disquiet about 'high-risk adventure tourism' — in which category it clearly included independent expeditions (COMNAP 2002: paragraph 15). Acknowledging that these activities posed 'low environmental risks,' the statement's main concern was that 'national operators may not be able to recover the high costs associated with rescue and repatriation operations.' (This is because a legal framework based on the Madrid Protocol, and thereby concerned with environmental protection, may not be effective in this regard.) Much of the criticism directed at independent expeditions alludes to the disruption they may cause, should they require assistance, to science programs or commercial tourism operations, and sometimes to the harm they might cause themselves. The actual concern often appears to be more financial and to involve the question: will anyone who assists these expeditions be compensated? Since most national programs or tour companies feel an obligation to render humanitarian assistance in the case of an emergency, they find themselves having either to write the costs off or to seek regulations requiring expeditions to guarantee repayment or discouraging them from proceeding in the first place. Increasingly, the regulatory approach appears to be favoured.

The 'stringent guidelines' recommended by the UK in 2003 indicate some of the areas where control may be sought: "contingency plans e.g. SAR, medivac provisions, insurance, liability etc' (United Kingdom 2003). If the ATCPs adopt a strict regulatory approach, it is likely that prospective expeditions will be minutely vetted. Under scrutiny would be such things as: the experience and fitness of members, equipment, conformity with Environmental Impact Assessment requirements, contingency plans for SAR and medical evacuation, and insurance arrangements to cover the costs of any assistance required or liability incurred. While this appears reasonable, it should also be remembered that emergency assistance the basis of many of the concerns - is only required by those expeditions which get into difficulties. Of those described above, some needed no assistance; others required fuel, food, temporary accommodation or transport; and only three involved injury and rescue. Assessment of the true extent of the problem would be helped if data were available on the frequency of interaction of independent expeditions with national programs and mainstream tourism operations, and of the actual consequences and costs of that interaction. 
In any case, the Madrid Protocol is concerned with the protection of the Antarctic environment, and debate about adventure tourism and independent expeditions should not be allowed to obscure the fact that the threat these pose to the environment is miniscule by comparison with that posed by science programs and mainstream tourism. Historical damage to the physical environment and wildlife by government programs is well documented, and the Bahia Paraiso disaster gives a clear indication of the potential for harm of the large cruise ships that are visiting the region in increasing numbers.

\section{Implications for independent expeditions}

In a 1998 article for National Geographic, Jon Krakauer referred to 'the staggering logistic and financial hurdles that must be overcome to mount any kind of private expedition to Antarctica' (1998: 56). For aviators like those previously described, arrangements for refuelling are particularly complex and can be fraught with difficulty. Caching fuel will require the assistance either of a national program, which may be denied, of a tourist ship, or of ALE/ANI. The last option may not be available and in any case is likely to be costly: in the Patriot Hills in 1988 Dick Smith paid US $\$ 30,000$ for 10 drums of fuel, previously flown from Punta Arenas (1991: 111). Although these expeditions often involve years of preparation, in Antarctica this may not render them proof against the epithets 'ill-prepared' and 'irresponsible' (IAATO 2003). In part the problem is one of classification. As long as small independent expeditions are regarded as tourist ventures, they can be assessed against corporate standards, which are correctly applied to large commercial operations or government programs but which are inappropriate to them. This results in their being labelled 'responsible' or 'irresponsible' according to inapplicable criteria (Fig. 1).

The second of the major challenges for independent expeditions alluded to by Krakauer was financial. Apart from the costs of equipment, fuel, and supplies, there is the cost of 'support.' This term is another that has never been substantively defined. It is used to refer to, among other things, adequate SAR back-up, selfsufficiency, trained and experienced staff, and adequate insurance. ALE/ANI is now the chief supplier of 'support' to non-government expeditions in Antarctica and in 2000 'the average cost per person for expedition support was around US\$100,000' (Tracey 2001: 67). Ann Bancroft and Liv Arnesen's 2000/01 'Your Expedition' estimated the costs of operating a support ship and ANI air cover had been 'in the region of US\$250,000-300,000' (ANAN Archive: 41/06). Expenditure of this order is clearly prohibitive for many, but it is unlikely that independent expeditions could secure official approval without it, and perhaps it is for this reason that some choose not to disclose their intentions fully. Bae and Sønneland later admitted to this, although the reason they gave was a wish to surprise everyone after the event in the manner of their countryman, Roald Amundsen (ANAN Archive: 42/05). According to Sir Ranulph Fiennes, Amundsen's own reasons for concealing his plans were much more pragmatic. Certainly he wanted to take advantage of the fact that Robert Scott did not know he had a competitor in the quest for the South Pole, but "he also knew that all his sponsorship and the ship he had "borrowed" from Nansen would be forfeit if he publicly announced this change of plan. He was heavily in debt, which did not help...' (Fiennes 2003: 157). A contemporary Antarctic expeditionist faced with the possibility of having a venture forestalled if plans were fully disclosed might sympathize with Amundsen's choice. Judgements of the methods employed will in any case very likely be affected by an expedition's success or failure. Scott himself showed a clear understanding of this. Writing to his agent in New Zealand immediately before setting out for the Pole, he remarked, 'If he [Amundsen] gets to the pole... one guesses that success will justify him... If he fails, he ought to hide!' (Solomon 2001: 170).

Antarctica is a uniquely hostile environment and it would be foolhardy for anyone to venture there in ignorance or poorly prepared. It would also be unfortunate if regulation became so restrictive that any possibility of risk was denied. Risk-taking is not looked upon favourably today. Plagued by high insurance premiums and the threat of litigation, certain societies have become decidedly 'risk averse.' Vastly increased information has brought with it more to fear, and great effort is expended in attempts to make the future as secure and predictable as possible. Up to a point this is prudent, but something may also be lost. To do anything new implies a degree of risk, a willingness to step outside the security of what is already known. Chance is possibly involved, and one may succeed or not. But without this element of risktaking it is doubtful how far the human race would have developed. What is certain is that nobody would be able to go to Antarctica today. In the future, it is possible that a question like the following could arise: if a reasonably well-prepared expeditionist was given clearly to understand that assistance would not be available and that person accepted the risk of death, should they be prevented from going to Antarctica? 'We took risks, we knew we took them; things have come out against us, and therefore we have no cause for complaint...' Thus wrote the dying Scott (Barrie 1923: 477).

\section{Benefits of independent expeditions}

The debate about non-governmental activity in Antarctica, occurring as it does largely among the most powerful vested interests — national science programs and IAATO generally gives the impression that assistance and benefits flow only in one direction: from government programs, and less frequently IAATO members, to the independent expedition. Given that the former groups represent the overwhelming proportion of people who visit Antarctica, and given the resources at their command, this is no doubt broadly true. However independent expeditions have also brought benefits. Smith (1991) assisted the Australian program with scientific work and by demonstrating the 
capabilities of fixed-wing aircraft for Antarctic use. Similarly, as a nascent commercial operation, ANI proved the possibilities of blue-ice runways, which are extremely cheap both to build and to maintain (Swithinbank 1993). For many years glaciologist Charles Swithinbank and Antarctic pilot Giles Kershaw had been convinced that 'bare ice landing strips would benefit government operators as much as [private expeditions]. But it was clear that no government would commit transport aircraft to landing on icefields until the concept was proven' (Krakauer 1998: 61). Ironically, the US government attempted to block the first test flight in 1987, as part of its concerted effort to prevent all non-governmental expeditions from visiting the continent (Krakauer 1998: 56). Independent expeditions can also attract wide public attention via films, lectures, articles, books, and the media. As Bauer pointed out, 'by sharing their adventures with the general public, Antarctic adventurers, historic and contemporary, stimulate the interest of the public in Antarctic affairs in general and in tourism in particular... breaking ground for more mainstream tourists to follow in their footsteps' (2001: 109).

\section{Conclusion}

This article has pointed to the lack of clarity in the terminology used to describe different kinds of activity in Antarctica and proposed a possible classification. The confusion to date has not allowed proper consideration of the actual motives behind independent expeditions, their non-commercial nature, or the high levels of expertise and planning some of them exhibit. Instead they have been assessed against standards appropriate to corporate enterprises and sometimes found wanting. Debate about permissible activities in Antarctica is dominated by two blocs: national science programs and IAATO. The right of the former to pursue their aims is rarely questioned, and while there are now national policies to limit all non-governmental activities in Antarctica, including mainstream tourism (see, for example, New Zealand 2003), in general the latter is considered legitimate and its conduct praiseworthy. This has resulted in a degree of attention being focused on independent expeditions that is out of all proportion to the relative numbers of people involved and the potential threats to the Antarctic environment.

The region will surely continue to attract people with a range of motives and travelling via a variety of modes. It has not been the intention of this article to prescribe policy towards them but, noting the increasing concern about independent expeditions and certain problems in the debate, to put forward alternative points of view in the hope of better informed and less polarized discussion in the future. Antarctica has a unique symbolism and history: of cooperation in the midst of conflict, of a peerless solution to territoriality, and of the highest adventure and enterprise. There are serious concerns about the environmental impacts of all who go there; there are also legitimate questions regarding possible disruption to national programs by others who visit the continent. However an uncompromising, heavy-handed attitude towards the control or prohibition of a small number of independent expeditions is misguided and also threatens Antarctic values that are perhaps more significant than any activity undertaken there.

\section{Acknowledgements}

This work was supported by the Australian Government's Cooperative Research Centres Program through the Antarctic Climate and Ecosystems Cooperative Research Centre (ACE CRC). The authors thank Professor Bruce Davis for comments on a draft version of the paper.

\section{References}

ANI. Undated a. Home page. URL (accessed 05-05-04): http://www.adventure-network.com

ANI. Undated b. Extreme. URL (accessed 0505-04): http://www.adventure-network.com/subpage. asp? navid $=1 \& \mathrm{id}=15$

ANAN. Archive. URL (accessed 11-05-04): http://wwwold.antdiv.gov.au/goingsouth/tourism/News/default.asp

ANAN. 2003. 2003 ANAN Issues. URL (accessed 11-0504): http://www.aad.gov.au/default.asp?casid=4974

ATCPs. 1966. Final report of the fourth ATCM, Santiago, 3-18 November 1966.

ATCPs. 1975. Final report of the eighth ATCM, Oslo, 9-20 June 1975.

ATCPs. 1979. Final report of the tenth ATCM, Washington, DC, 17 September-5 October 1979.

ATCPs. 1991. Final report of the sixteenth ATCM, Bonn, 7-18 October 1991.

ATCPs. 1992. Final report of the seventeenth ATCM, Venice, 11-20 November 1992.

ATCPs. 1994. Final report of the eighteenth ATCM, Kyoto, 11-22 April 1994.

ATCPs. 2003. Final report of the twenty-sixth ATCM, Madrid, 9-20 June 2003.

Barrie, J.M. (editor). 1923. Scott's last expedition: the personal journals of Captain R.F. Scott, RN, CVO, on his journey to the South Pole. London: John Murray.

Bauer, T.G. 2001. Tourism in the Antarctic: opportunities, constraints and future prospects. New York: Haworth Hospitality Press.

Boczek, B.A. 1988. The legal status of visitors, including tourists, and non-governmental expeditions in Antarctica. In: Wolfrum, R. (editor). Antarctic challenge III. Berlin: Duncker and Humblot: 455-561.

Chiang, E. 2000. Tourism risks from an operational perspective. In: Proceedings of the Antarctic Tourism Workshop June 2000. Christchurch: Antarctica New Zealand: 25-28.

Commonwealth of Australia. 1989. Tourism in Antarctica. Report of the House of Representatives Standing Committee on Environment, Recreation and the Arts. Canberra: Australian Government Publishing Service.

COMNAP. 2002. Interaction between national operators, tourists and tourism operators. Information paper 27 for XXV ATCM, Warsaw, 10-20 September 2002.

Enzenbacher, D.J. 1992. Tourists in Antarctica: numbers and trends. Polar Record 28 (164): 17-22.

Enzenbacher, D.J. 1994. Antarctic tourism: an overview of 1992/93 season activity, recent developments, and emerging issues. Polar Record 30 (173): 105-116. 
Fiennes, R. 2003. Captain Scott. London: Hodder and Stoughton.

Gee, C.Y., and E. Fayos-Solá (editors) 1997. International tourism: a global perspective. Madrid: World Tourism Organization.

Lindsay, A. (director). Hell on ice. 2004. Video recording. Melbourne: Vue Pty; and Dunedin: Natural History New Zealand.

Herr, R.A. 1996. The changing roles of non-governmental organisations in the Antarctic Treaty System. In: Stokke, O.S., and D. Vidas (editors). Governing the Antarctic: the effectiveness and legitimacy of the Antarctic Treaty System. Cambridge: University Press: 91-119.

IAATO. 2002. Chairman's report from the Aspen meeting on Antarctic tourism. Information paper 30 for XXV ATCM, Warsaw, 10-20 September 2002.

IAATO. 2003. Adventure tourism in Antarctica. Information paper 96 for XXVI ATCM, Madrid, 9-20 June 2003.

IAATO. Undated a. Homepage. URL (accessed 13-01-04): http://www.iaato.org

IAATO. Undated b. Bylaws. URL (accessed 13-01-04): http://www.iaato.org/bylaws.html

IAATO. Undated c. Contributions to science, research and the environment. URL (accessed 13-01-04): http://www.iaato.org/iaato_science.html

Krakauer, J. 1998. Queen Maud Land: on the edge of Antarctica. National Geographic February 1998: 46-69.

New Oxford Dictionary of English. 1998. Oxford: Clarendon Press.

Newsome, D., S. Moore, and R. Dowling. 2002. Natural area tourism: ecology, impacts and management. Clevedon: Channel View Publications.

New Zealand. 2003. NZ backs stronger management of
Antarctic tourism. Media statement, 22 May 2003, by Hon. Phil Goff, Minister of Foreign Affairs and Trade.

Oxford English Dictionary. 1989. Second edition. Oxford: Clarendon Press.

Scott, S. 2001. How cautious is precautious? Antarctic tourism and the precautionary principle. The International and Comparative Law Quarterly 50 (4): 963971.

Smith, D. 1991. Our fantastic planet. Terrey Hills: Australian Geographic.

Solomon, S. 2001. The coldest march: Scott's fatal Antarctic expedition. Carlton South: Melbourne University Press.

Swithinbank, C. 1993. Airborne tourism in the Antarctic. Polar Record 29 (169): 103-110.

Tracey, P.J. 2001. Managing Antarctic tourism. Unpublished PhD thesis. Hobart: Institute of Antarctic and Southern Ocean Studies, University of Tasmania.

United Kingdom. 2003. Proposals to improve the management and regulation of Antarctic tourism. Working paper 23 for XXVI ATCM, Madrid, 9-20 June 2003.

Urry, J. 1990. The tourist gaze: leisure and travel in contemporary societies. London: SAGE Publications.

United States. 2002. Handbook of the Antarctic Treaty System. Ninth edition. Washington, DC: US Department of State.

Weaver, D. 1998. Ecotourism in the less developed world. Oxford: CAB International.

Weaver, D., and M. Oppermann. 2000. Tourism management. Brisbane: John Wiley and Sons Australia.

Yelverton, D. Undated. Emergency landing of aircraft on Marion Island. Unpublished report by Marion Island station leader. Pretoria: Department of Environmental Affairs and Tourism. 